\title{
Més fonts de Lo somni de Bernat Metge
}

\author{
JÚLIA BUTINYÀ JIMÉNEZ
}

UNED

Pot tenir utilitat d'aplegar les fonts que he exposat a dos darters Congressos (a l'octubre del 2000) 1 i que, junt amb les que aniran apareixent en publicacions en aquest inici de segle ${ }^{2}$, ofereixen una panoràmica de Lo somni que, més que nova, el que fa és subratllar l'antiga visió de l'obra com a humanista. Cal dir a l'avançada que aquesta aportació és coherent amb el gruix de les fonts que recollia l'edició d'Obras de Bernat Metge del 1959, a cura del Dr.Riquer, la qual seguirem (OBM) ${ }^{3}$.

Cal comentar també a l'avançada que les fonts agustinianes, així com les de Filosofia en general, seran esmenades en la mesura que calgui per les professores especialistes al sant i que estan estudiant Metge ${ }^{4}$.

No és aquest tant un treball de crítica com d'exposiciós, per això crec que És més expeditiu de seguir el criteri d'agrupació per autors i obres, que es projecten sobre el diàleg català, i no el de seguiment dels llibres que el componen. Amb tot, procurarem una certa ordenació, bo i començant, a causa de la seva rellevància, pels trescentistes italians.

1 La recepción de Boccaccio en España. Universitat Complutense, i Literatura: historia o propaganda (Els precedents literaris medievals de la manipulacio mediàtica, Universitat de València.

2 S'han indicat a les referències bibliogràfiques, en premsa. De tota manera, per a una vjsió més àmplia n'estic preparant una monografia. en la línia que vaig iniciar a Tras los orígenes del Humanismo: El «Curial e Güelfa»: Tras los origenes del Humanismo: Bernat Metge.

${ }^{3}$ Al meu entendre, des d'aquesta edició. que les aplegava fins a la dara, cal afegir les del $D e$ natura deorum, Boeci, Juvenal i Valeri Màxim (Cingolani 1999) i 1'Hercules furen.s (Badia 1991-1992).

4 Em refereixo concretament a M. Ángeles Navarro, de la Universitat de Comillas, i a Paula Silva, de Lisboa. Així mateix, quant a les fonts amb més detall, he de remetre a l'esquema o hipotext que publicare dins l'estudi que fem conjuntament: Tres mirades cientifiques sobre aLo somni de Bernat Metge.

5 I el presento a tall d'apunt. De tota manera faré per explicar els motius de reconeixement de la font, situació, condicions, etc. i aplegarem a una conclusió. 
La primera referència clàssica que donem i que es pot reconèixer en fàcil imitatio és la de Suetoni6, i és molt expressiu que ens vingui a través d'una epïstola senil adreçada a Boccaccio (XVII, 2), car ja ens situa a la dinàmica precisa en què es desenvolupa tot Lo somni.

L'ombra petrarquesca ens ve avalada per la juxtaposició al mateix passatge del De remediis (II, 119), en punts d'innegable semblança i que en donen una lectura en clau espiritualista, excloent gairebé la preocupaciố per la situació real, que és la que semblava destacar com a mòbil materialista del diàleg. Lectura, doncs, que s'oposa de ple a la que es venia mantenint com a interessada per part d'un home oportunista:

«Etsi enim dicat Anneus quosam invitos senectutem audire et canos et alia, ad que votis pervenitur ${ }^{7} 7$, idque ego non quibusdam sed pene omnibus evenire consentiam, non tamen hanc etatem plusquam ceteras erubesco. Quid enim magis senuisse me pudem quam vixisse? cum alterum sine altero diu esse non possit. (...) Ideo adhuc nitor, siquo modo forsan ad vesperam diurnam desidiam reparare contingeret et sepe michi per animum recursat seu cesareum illud sapientissimi principis Augusti: Sat celeriter fieri quicquid fiat satis bene" (Senils XVII, 2).
«Puys, si'l serveys, te'n sabrà ben remunerar. Però a tu no te'n cal fer gran noves, car bé.l coneys. -Senyor -diguí yo-, ver és, $\mathrm{e}$ aytal speranse he yo en ell; mes a present no'n veig venir les mars. -O! -dix ell-, comuna malaltia és dels hòmens que co que molt desigen no creen que yamés los venga, o si.ls ve, és tard a lur parer.

$-A b$ que vinga qualque die, Senyor-diguí yo-, bé'n seré content, car prou se far tost şo que bé.s $f a »(\mathrm{OBM} I \mathrm{176}, 9-13)$.

«qui autem omnia bona a se ipsi petunt, iis nihil malum potest uideri quod naturae necessitas adferat. Quo in genere est in primis senectus. Quam ut adipiscantur omnes optant, eandem accusant adepti: tanta est stultitiae inconstantia atque peruersitas!», Cato maior. II, 4, p. 84.

La referència al De senectute és mol eloqüent perquè conté la correcció a Petrarca, qui donava erròniament l'autoria d'una citació, en Sèneca, quan procedia d'aquella obra ciceroniana que tan bé coneixia el nostre autor. Ara bé,

6 Vegeu el treball a "Annals de l'Institut d'Estudis Gironins" (2000), p. 42.

7 La citació és de De constantia sapientis 17,2, tot i que prové del De senectute, com bé devia adonar-se 'n Metge, com sembla mostrar la frase en negretes ( $\mathrm{O} ! m .$.$) , que glossa aquella$ ciceroniana enlloc de la senequiana. 
l'esmena es dóna d'una manera exquisita: plagia el text de Cicerố al lloc on havia d'haver comptat amb el text senequià.

Dos aspectes semàntics, que suposen dues esmenes a Petrarca, hi contribueixen tambć al reconeixement. Vegem en primer lloc que la idea de la Fortuna petrarquesca que s'hi manifesta a la senil en retreure a Boccaccio el seu plany davant la mala sort es contesta al llibre IV8, al començament del qual ens situa en aquest tema, bé que ací ja, des del començament i sembla que de manera paral.lela, Metge també s'ha dolgut de la mort a causa del seu amic. EI català, per contra, fa seva una idea providencialista, de caràcter positiu i envidat, en comptes del negatiu $i$ amarg de l'italià, la qual expressa mitjançant un clàssic: Juvenal.

"permittes ipsis expendere numinibus quid

conueniat nobis rebusque sit utile nostris.

Nam pro iucundis aptissima quaeque dabunt di;

carior est illis homo quam sibi.» (Sàtires X, vv. 347-350, p. 137).

"Quant és a present, de assò no cur molt; so que a Nostre Senyor Déus plaurò e a ell, serà plasent a mi» (OBM I 176, 13-14).

És significatiu que també a començaments del llibre següent -factor que ens pot servir com a ratificació-, ran de l'única citació no bíblica explícita en aquest llibre, la del De remediis (II, 113; OBM II 234, 1-5 i n. 3), es torna a donar el mateix reflex de fonts en combinació: el De seneciute (XIX, 66-71; X, $33)^{9}$, i -utilitzant els mateixos capítols i poema:- el De remediis (II, 119) i la sàtira $\mathrm{X}$ de Juvenal.

«Fortem posce animum mortis terrore carentem, qui spatium uitae extremum inter munera ponat naturae» (Sàtires, X, vv. 357-359, ib.).

«m-és viyares que sia gran cosa ésser quit de pahor de morir, car, a mon juý, la piyor cosa que en lo morir entrevé és la pahor de la mort." (OBM II 234, 7-11)...

* Metge s hí oposarà en rodó a l'accitud de l'italià (Butinyà 1994 a), en paràgrafs ben signjficatius, que bé va entendre l'autor del Tiramt lo Blanc (Butinyà 1998).

9 La indiquem com a remesa, aixi com a la criilla anterior la del De remediis II 119 , per tal com hi coincideixen $i$ és un fet que les coneixia si les utilitzava; ara bé, les que exposem semblen més absorbides a cada Iloc i situació. 
(...) Es intolerable que alguien llore por lo que es su condición natural. No morirías si no fueras mortal (...) La naturaleza, madre benigna de todas la las cosas, no hizo ninguna horrible. No es ella la que causa el temor a la muerte, sino el el error de los hombres. (...) Haz de buena gana lo que tienes que hacer de todos modos. Bien lo dijo el que tuvo óptimos consejos sobre la muerte: "Lo que no puedes evitar, hazlo de buena voluntad" "(Remedios contra la buena y la mala suerte, p. 180 ).
"Cosa natural és morir, axí com néxer, menyar, beura, suar, dormir, sedeyar, famayar, vetlar e semblantz cosas; e alguna natural cosa de si matexa no és mala ne terribla, mas la oppinió dels hòmens la fa vegades ésser aytal. No és stat home qui sia nat qui no muyra, ne qui muyra que no sia nat. ¿Quèns cal fer, donchs, gran festa de assò que cascun jorn veem, e què.ns proffita tembre assò que no podem esquivar?" (OBM II 234, 16-22).

La llatinista Leticia Carrasco em suggereix la font de la Jletra a Lucili LXVII del llibre VII 10 :

«quod effugere non possis, quam fortissimi ferre», «Les Belles Lettres», p. $136^{11}$.

El De remediis el tornem a trobar en punts idonis: així en una frase afegida al text que segueix del De amicitia, i d'un capítol (II, 52) que s'hi avé amb molta lògica: «La mort de l'amic», ja que s'hi troben parlant de la mort d'Escipió, recordada per Lelius, la qual fa de ressò de la del rei, aportada ací pel seu amic $^{12}$. L'afegit petrarquesc (en negretes) ${ }^{13}$ formula una idea que és cabdal a Lo somni, que la seva tranquilitat jeu al convenciment que l'amic no pateix cap mal a causa de la seva virtut:

10 No he localitzat encara una edició anotada (1997) d'aquesta carta petrarquesca; per tant, anem una mica a les palpentes.

11 Trad, de la «Fundació Bernat Metge» (v. II, a cura de C. Cardó, Barcelona 1929, p. 51): «la prudència... que et determina a suportar al més coratjosament possible allò que no pots evitar».

12 Bé mostra el que diem del paral-lel el fet que immediatament $(202,14-20)$ faci referència al prèstec -entre el rei $i$ el seu amic- del llibre ciceronià que recollia llur conversa sobre la immoralitat, emprant un preciós recurs de tècnica literària de mirall, sota el joc de l'obra dins l'obra.

13 «Por Tulio sabes que Lelio se consuela pensando que su amigo Escipión está vivo porque no ha muerto ni su fama ni su virtud» $(1999, p .147)$. Cal notar que al Lelius la idea sortia amb una expressió no tan semblant (XXVIII, 102). 
«Nihil enim mali accidisse Scipioni puto: mihi accidit, si quid accidit; suis autem incommodis graviter angi, non amicum, sed se ipsum amantis est.» (De amicitia, III, 10, p.18).
«No pens que mal sia esdevengut a Scipió, car virtuosament ha viscut; a mi és vengut, si esdevengut és. Esser greument torbat per son propri damnatge no és de amich, mes de amant si matex» (OBM I 202, 6-9).

També sembla estar present el tractat petrarquesc quant a les escissions, al capítol sobra la guerra civil, car en un lloc i altre es passa a donar tot un conjunt de mesures que s'hauria pogut fer:

«Si te ves impotente, intenta convencerlos amenazando, rogando, interponiéndote, censurando, haciéndoles ver la destrucción general...» De remediis $\mathrm{II}, 74$, $\mathbf{p}$. 154.
${ }_{i E}$ E quina manere e remeys -diguí jo- me podien ells donar? Fort ho volria saber.'... E los remeys són: pus tant ne eres anat avant, que treballasses e fesses ton poder... (OBM II $242,10 \ldots 16$ ).

I sembla treure també d'aquí (II, I16) un comentari afegit, quan ha acabat el relat biogràfic ovidià sobre Tirèsias 14 :

«Tiresias, de quien antes hemos hablado, era completamente ciego y fue famoso por sus visiones y presagios" (De remediis II, 96, p.167).
«E mentre visquí en lo món, doné moltas respostas veras de assò que la gent me demanava que-s devia seguir en lo esdevenidor» (OBM III 284, 24-25).

Les intertextualitats del Trattatello in laude di Dante -que a vegades troben ressò a /l Comento alla Divina Commedia - són abundants: així a Jes pàgines $166 ; 230 ; 246 ; 252 ; 256 ; 286$... Tot i que potser el fet més simptomàtic de l'ascendència de Boccaccio sigui la glossa que fa a sant Agustí amb un text del certaldès:

14 Tret que pot estar carregat d'ironia tenint en compte l'afecció del rei difunt per l'endevinació i la interpretació pecaminosa. 
«Ella è allora chiamata 'ani$m a^{\prime}$, quando ella vivifica il corpo; ella è chiamata 'animo' quando ella alcuna cosa vuole; ella $\grave{e}$ chiamata 'ragione', quando ella alcuna cosa dirittamente giudica; ella è chiamata 'spirito', quando ella spira; ella è chiamata 'senso', quando ella alcuna cosa sente; ella è chiamata 'mente', quando ella sa ed intende" (Il Comento, III, p. 202). "què és spirit o ànima, car en lo cors humanal una matexa cosa són. Mas segons la diversitat dels officis que la dita ànima exercex, és en moltes maneras nomenade. Car vivifficant lo cors és apellade ànima; e volent, coratge; sabent, pensse; remembrant, memòria; justament judicant, rahó: e inspirant, spirit. Emperò, la sua essència una sola és e simpla" (OBM I 176, 31-178, 3)15.

Apreciem que Metge l'ha seguit en aquest petit tractat molt fidelment en alguns casos, com ara en aquesta explicació bíblica:

«non pare a'santi in alcuna guisa si debba credere che alcuna anima dannata, e molto meno l'altre, per alcuna forza d'incantamento si possa trarre d'inferno $e$ rivocare per cagione alcuna in questa vita. E se forse a questa veritá s'opponesse molte essercene state già rivocate per forza d'incantamenti, e tra l'altre quella di Samuel profeta, il quale quella pitonessa, a'prieghi di Saul re, gli fece venire a rispondere di ciò che gl'intervenne, ovvero che intervenir gli dovea; dico questo essere del tutto falso; percioché i santi tengono quello non essere stato Samuel, ma alcuno spirito immondo...», Il Comento III, p. 7.
«Saül dix a una fembra phitonissa que li phaés ressuscitar Samuel, qui era mort; e axí fou fet, e parlà ab ell. Lo qual Samuel li dix que l'endemà morria ab sos fills e seria ab ell; puys, seguí's axi com li havia dit. Alguns, emperò, affermen que no li aparech la ànima de Samuel, mas un diable en forma sua; altres dien que sí féu. Sia que.s vulla, la Sancta Scriptura diu que Samuel li aparech. La istòria és largament contenguda en lo Primer libra dels Reys, vers la fi: dich.la't superficialment; en aquella poràs veura si les ànimas viuen aprés la mort corporal» (OBM I 208, 20-29).

Crec que és un fet que Metge, reconeixent l'altura dels tres grans trescentistes, se situa a Boccaccio, el qual imita principalment, i de qui pren conceptes molt principals $\mathbf{i}$ amb qui explica els grans textos sagrats. Autor de doctrina amorosa -com ho podia ser Ovidi, a qui posa com a profeta-, i en qui estranya-

15 «itane tu ignorabas duo quaedam esse animam et spiritum (...) ut totus homo sit spiritus el anima et corpus", De natura et origine animae, 1982, pp. 736-737. 
rà i escandalitzarà la ideologia misògina, que satiritza als dos darrers llibres de Lo somni, tot i que el seu llenguatge esplèndid permeti tothora un plagi d'imitació ben puntual; actitud literària que cl certaldès admirava en Dante respecte als clàssics 16 .

Ara bé, d'aquella incongruència moral en responsabilitzarà Petrarca, posat que coneixia bé la seva ascendència espiritual, ben palesa a llur correspondència, que tan bé coneix i així ens ho fa veure. Bona mostra és aquesta petja petrarquesca en cloure el recit boccaccesc i el llibre III:

«Iam tunc clarum et insigne presagium, quid de societate feminea sperare posteritas deberet" (De vita solitaria II, p. 418).
«Ara veus què pots sperar de aquest maleÿt linatge femení.» (OBM 318, 21-22).

I això, quintaessenciat, és Lo somni, segons l'explicació que hem donat als nostres treballs, que es donen a la bibliografia ${ }^{17}$. Fora del I llibre que és ben bé un cas a part ${ }^{18}$.

Continuarem, doncs, explicant detalls, que complementen aquesta interpretació amb altres fonts que s'hi adiuen. El Convivio és omnipresent al II llibre, però en destaquem una petita frase de gust ennoblidor $i$ ascendència aristotèlica, ben triada per a una ocasió oportuníssima d'alta noblesa, per al-ludir a l'excepcionalitat de la Mare de Déu entre les dones:

«una rondine non fa primavera», Convivio I, 9. «una flor no fa primavera», OBM IV 324, 18.

De Genealogie deorum, fora d'algun petit detall, com ara la referència a Manto, la filla de Tirèsias (III 284, 1-2) o els trossos que n'aprofita per a la descripció infernal ${ }^{19}$, cal destacar la referència tan significativa del Griselda al IV

16 Nel quale esercizio familiarissimo divenne di Virgilio, d'Orazio, d'Ovidio, di Stazio e di ciascuno altro poeta famoso; non solamente avendo caro il conoscergli, ma ancora, altamente cantando, s'ingegnò d'imitarli... (Trattatello in laude di Dante, 443, 22)
De Virgili, Sènecha, Ovidi, Oraçi, Luchd, Staci, Juvenal, e molts altres poetas te dirie ço que-n han scrit, mas tu has aquells tant familiars. que no seria àls sinó empènyer ab la mà la nau quan ha bon vent. (OBM 206 , 22-25)

17 Quant al protagonisme i rellevància de Boccaccio, vegeu les Actes del Congrés esmentat a la n. 1 supra.

18 Tot i que la unitat del diàleg és una de les seves grans consecucions, aplegant matèries i estils tan diferents, n'he tractat de la seva caracterització a l'Homenatgé al professor Montoya i, quant al final del llibre, que entenc com a una correcció al tomisme, al «Butlletí de la Reial Acadèmian.

19 Tan sols a tall de mostra: 
llibre20. Amb tot, s'hauran de localitzar molts més punts, que combinen o complementen les fonts clàssiques del III llibre amb determinada intencionalitat.

Hi ha també idees amb què combreguen tots dos autors, Dante i Boccaccio, com ara la salvació dels pagans, tema en què Metge ens fa palesa directament la seva ironia, d'una banda, i la trascendència que li dóna al tema, d'una manera indirecta de l'altra, perquè ja havia comentat al llibre I que la necessitat de justícia era el primer argument per a l'existència d'un Déu. Metge conjuga totes dues fonts boccaccesques, bevent el florentí mitjançant el certaldès, fent aquest de mitjancer ${ }^{2}$, a l'igual que abans havíem vist que ens aportava els clàssics a través de Petrarca:

"Così si mise e cosi mi fé intrare nel primo cerchio che l' abisso cigne.

Quivi, secondo che per ascoltare, non avea pianto mai che di sospiri

"Finxere tamen poete has apud inferos esse damnatas, et hoc assidue agitari supplicio ut haurientes aquas urnas absque fundis conentur implere, ut dicit Ovi. dius: 'Molirique suis letum patruelibus ause Assidue repetunt. quas perdant belides undas' etc. Et Seneca tragicus in Hercule furente (...) Apponuntur enim talibus Arpye ...ut etiam aliquando cibum sumere efficiantur immemores ... sibi ipsis cibos extenuant et sua miseria fedos faciunt» (Genealogie deorum gentilium. II, 23, p. 226; IV. 59. p. 486).

20

"Sed etiam nullam esse usquam tam delirantem aniculam, circa foculum domestici laris una cum vigilantibus ybernis noctibus fabellas orci, seu fatarum, vel lamminarum. et huiusmodi, ex quibus sepissime inventa conficiunt, fingentem atque recitantem, que sub pretextu relatorum non sentiat aliquem iuxta vires sui modici intellectus sensum minime quandoque ridendum...) (Genealogia dcorum gentilium. XIV, $X, 970$ )
«E assí comensa hom de intrar en infern, en lo qual ha diverses habitacions, ceparades les unas de las altres. En la primera

"Altres meten contínuament ayga en verells qui no han fons, $e$ cuyden-los com. plir e treballen en wa e no poden, per tal com han desiyat mort d'altra e anelat a aquella, jatssia no hagen pugut lur desig conplir... Altres són çechs e sens uylls, e tenen devant raules ben parades ab molta bona vianda, e vénen arpies, qui són ogells ab cares de donzellas $e$ ab peus de guall, que los leven les viandes devant e puys ensutzen-los les taules, per tal com vivent exorbaren e maltractaren lurs fills per complaure a llurs mullers, madrastres de aquells" (OBM III 274, 14-24).

"La pasciència, fortitut e amor conjugal de Griselda, la istòria de la qual fou per mi de latí en nostra vulgar transportada, callaré, car tant és notòria que ya la reciten per enganar les nits les velles en les vetles e com filen en ivern entorn del fochn (OBM IV 336, 21-24).

21 Caldrà estudiar algun dia aquest important paper de la literatura, com a revitalitzadora $\mathbf{i}$ filtre dels textos. Perquè mai no se l'ha considerat a Metge filòleg, car no es dedicava com els italians a tasques d'edició i recerca: però el seu tractament rigorós del text i la transmissió tan fjdedigna, formalment $\mathrm{i}$ semàntica, ens ho poden fer reconsiderar. 
che l'aura etterna facevan tremare;

ciò avvenia di duol sanza martìri, ch'avean le turbe, ch'eran molte $e$ grandi,

d'infanti e di femmine e di viri...

Or vo' che sappi, innanzi che più andi,

ch'ei non peccaroie s'elli hanno mercedi.

non basta, perché non ebber battesmo, ch'è porta de la fede che tu credi...

Gran duol mi prese al cor quando lo 'ntesi,

però che gente di molto valore conobbi che' n quel limbo eran sospesi. ...

'uscicci mai alcuno, e per suo merto o per altrui, che poi fosse beato?'...

rispuose: 'Io era nuovo in questo stato, quando ci vidi venire un possente con segno di vittoria coronato...

Stavvi Minòs orribilmente e ringhia: essamina le colpe ne l'intrata; giudica e manda secondo ch'avvinghia.

Dico che quando I anima mal nata li vien dinanzi, tutla si confessa; e quel conoscitor de le peccata

vede qual loco d'inferno è da essa;"

(Divina Comèdia I: cant 4, 23-30, 33$36,43-45,49-50,52-54 \ldots$ 5, 4-10, pp. 89-91, 99). stan les ànimas dels infants, e generalment de tota persona que no hage resabut babtisma, posat que hage ben viscut en lo món. $\mathrm{E}$ no sofferen pena alguna, sinó tant solament gran tristor com no poden ne speren haver salvació. $E$ assí stan los gentils philòsoffs e poetas... e han aproffitat a molts en lo món, entre los quals stam Tirèsias e yo, e no.n podem exir jamay, sinó quant Déu ho ordona, e puys tornam-hi. No.t pens, però, que aquells qui són condempnats a infern ne hisquen sinó en quant esguarde mutació de lach, no pas mutació de pena; car aquella nulltemps no.ls desempara. Los sancts pares, emperò, qui aprés la passió de aquell ver Déu e hom que tu adores foren trobats per Ell en la primera habitació de infern en què Tirèsias e jo som, no creegas ser a aquesta ley subjugats, car despuys que.n exiren nulltemps hi són tornats. - En altre habitació està Minos, molt cruel e terrible jutya, lo qual examina los demèrits de las ànimas aprés que $\cdot$ ls ha fet aquí devant ell confessar lurs delictas. Puys ... Is do la sentència que merexen» (OBM III 270, 727).

«i primi morirono infanti, come detto è, e questi secondi norirono non battezzati in etá perfetta... io non estimo che da creder sia, quatunque nella presente vita gl'infanti in tenerissima etá morissono, che essi sieno, al supplicio, in quella etá, cioè in quello poco o nullo conoscimento (...) Ed intende, in questa domanda, non di voler sapere de' santi padri che da Cristo ne furon tratti, che dobbiam credere il sapea, ma per ciò fa la domanda, per sapere se in altra guisa che in questa, cioè che fatta fu per la venuta di Cristo, alcun altro n' usci mai», Il Comento, II, pp. 8-11. 
De la Divina Comèdia, bé que es projecten també alguns conceptes bàsics, com ara la idea de justícia, de caritat, o el guiatge dels clàssics (pàgines 236, $244,324), n$ 'hi ha algun prèstec concret $i$ de fort relleu:

«Temer si dee di sole quelle cose male;

c'hanno potenza di fare altrui

de l'altre no, ché non son paurose», Divina Comèdia, I, cant 2, vv. $88-90$, p. 69 .
«Los delits - dix ell- en què jo ere inclinat no eren bastants tot sols a gitar-me en infern, car no eren interès ni dampnatge de algú, sinó de mi matex» (OBM Il 238, $1-3)$.

La moral cristiana, tot i que Metge no ho diu que ho sigui, no la fonamenta als grans pensadors que tan bé coneixia, ans la posa de costat al florentí en qui ell s'hi recolza.

El De claris mulieribus, per contra, i en bona lògica segons el tractament del terna misògin que pren del Corbaccio, més aviat es té present a mena de rèplica:

«Conclusio: In nostras usque feminas, ut satis apparet, devenimus quas inter adeo perrarus rutilantium numerus est, ut dare ceptis finem honestius credam quam, his ducentibus hodiernis, ad ulteriora progredi; et potissime dum tam preclara regina concluserit quod Eva, prima omnium parens, inchoavit" (De mulieribus claris, 780).
«Emperò, si no't anuig, parlaré 't breument de algunas de nostre temps, la virtut de las quals me força parlar pus prolixament que no cuydava (...) molt són stat prolix en mes paraulas; e per tal. jatssia que moltas altras virtuoses me acórregan, conclouré breument en la regina... ara regnant" (OBM IV $338,5-7 \ldots 344,1-3$ ).

Que el feminisme metgià és rèplica boccaccesca ho podria certificar així mateix I/ Comento, car ja sabem que acostuma a contestar un autor amb fragments del mateix autor:

“E, se per avventura alcuni quella dicono da dovere esser presa, e per la dispensazion della casa, e ancora per le consolazione che di lei si deono aspettar nelle infermità, e similmente... tutte queste cose farà molto meglio un fedel servo... che non fará la moglie", Il Comento, v. III, p. 219.
«No ignores que quan hom és sa o malalt, elles servexen pus diligentment $\mathrm{e}$ mils e pus netament que hòmens" (OBM IV 348, 13 14). 
Un passatge del llibre IV en què combina la tradició amb els clàssics, com havia fet en temes filosòfics tot al llarg del I llibre, és la lloa de les dones. Reconeixem el De senectute, on trobem la mateixa idea. La frase és molt peculiar, car deia Ciceró que sense vells no hi hauria ciutats, cosa que Metge aplica a les dones22:

«si nulli fuissent, nullae omnino ciutates fuissent", De senertute. XIX, 66, p. 124. «si donas no fossen stades... No foren ciutats, ni castells ni casas», 346, OBM IV, 28-30.

La segona part d'aquest magnific paràgraf pot rebre ressò del tractat II del Convivio que ha tingut tant a la vora $i$ on Dante deia que sense la seva Dama, la Ciència, no podria conèixer els fenòmens de la Naturalesa; així com del capítol II, 119 del De remediis, on es diu que la mort descorrerà el vel per saber totes les coses. La seva peculiar imitatio pot haver refòs les seves fonts amb una prosa espectacularment bella fent una preciosa laudatio a favor de la dona i d'ànsia científica 23 .

Hi diu que sense les dones «Algú no sabera lo moviment dels cels e de las planetas... ne ensercara les operacions amagades de natura...ne sabera perquè la mar infla...! » Tot i que al Corbaccio es deia a l'inrevés -que les dones fan que saben totes les coses de la naturalesa-, insistim que el text sembla imitar el Convivio, obra que ha estat com una ombra persistent, i al tractat II del qual s'afirma que sense filosofia moral amorosa no hi ha ciències, ja que els ulls de la dama -que són les seves demostracions-, adreçades als de l'enteniment, enamoren l’ànima. La dama de qui em vaig enamorar -diu Dante-, després del meu primer amor, fou la bellísima i honestíssima Filosofia. És ben sabut.

1 això és ben igual que Metge, qui també estimava la seva muller -diucom acostumen a estimar els marits (III 286, 1-2), i l'amant del qual ja havíem pensat que era simbòlica. Si hi apliquem una senzilla regla de tres, Metge ens està dient que estima i defensa una Filosofia al marge de l'oficial, cosa que de debò s'explica que enfurís Tirèsias rere el fet de fulminar una amant. Car aqueIla era encara molt més perseguida que les amants de carn.

De Cassiodor hem afegit, del mateix llibre que ja es coneixia, algun petit fragment que completa fonts ja conegudes d'altres tradicions, clàssica i bíblica $(1,188,12-17 ; 208,212,224)$.

22 Apereix el mateix recurs al De amicitia: "Quod si exemeris ex rerum natura benevolentiae coniuctionem. nec domus ulla, nec urbs stare poterir; ne agri quidem cultus permanebit” (VII. 23; pp. 36-38). Passatges que hi amplificaria Metge.

Tots dos autors encara ho han anticipat abans: Lo somni 334, 5-6, recordant Dido, i De senectute. punts 15, 17, 19, 20.

2.3 Paràgraf feminista per excel.lència, però que malauradament no es recull a cap estudi ni antologia sobre la dona, tant abundosos als nostres dies. donat el poc coneixement que se'n té de la gran obra de Metge: i en aquest punt no es pot pensar a una interpretació negativa ni burlesca. car el feminisme que es fa palès ací és univoc i rodó. 
De les fonts tan importants de sant Agustí en destaco poques perquè ês objecte d'estudi per part d'especialistes que ho podran assentar millor; amb tot, $m$ 'ha semblat reconèixer -a part de les principals que crec que són al I llibre: les Confessions i el De Civitate Dei-, entre altres, De ordine (OBM 224) i De Trinitate OBM 208, 234, 246, 254, 324). Veiem d'aquesta darrera, entre les virtuts de la vida futura, la nota que dóna el rei Joan envers la seva vídua; ocasió que n'és idònia per a un mort:

«Quod autem quisque penitus obliviscitur, nec commoneri eius utique potest» (De Trinitate XIV, 12,16, p. 673).
«Impossible és donar oblit a assò que hom ferventment ama» (OBM II 254, 4-5)

Quant als clàssics reconeix un deute o funció de pas amb els trecentistes i sant Agustí - així ja a la primera font a les Senils o degut a l'ascendència del De Civitate Dei; ara bé caldrà distingir molt finament si el fet de deixar net el mite d'Orfeu, treient-ne el pes de les moralitzacions que carregaven de culpa aquests herois amorosos, és efecte del pes racionalitzador del mite -com he mantingut darrerament- o bé -hi afegeixo ara-si es deu també al valor de l'al-legoria, a què recorria Dante i que ja va utilitzar Llull al Libre del gentil24. Car tot el diàleg té un important pes al.legòric i es té present àdhuc a l'encàrrec d'escriure l'obra, per via d'un lleuger reflex de Boccaccio'25.

Què fa Metge amb aquest esforç culturalista, que a sobre va amagar amb tant d'esforç? Doncs, si ho comparem amb el seu mestre -mestre al fi, be que el corregeixi moralment-, és molt significatiu, perquè el confidencial Secretum al costat de Lo somni era una obra propagandística; feta per ser llegida per tothom, com ara les epístoles petrarquesques; no n'hi havia cap mananent de

24 Llull i Dante, amb el recurs al.legòric, atorguen funció científica a la poesia, la qual cosa l'escolàstica negava. (Vegeu Curtius 1989, 320).

«Intende la divina Scrittura, la quale noi 'teologia' appelliamo, quando con figura d'alcuna historia, quando col senso d'alcuna visione, quando con lo 'ntendimento d'alcun lamento... mostrarci I"alto misterio della incarnazione... Così li poeti nelle loro opere, le quali noi chiamamo 'poesia', quando con fizioni di varii iddii, quando con trasmutazioni d'uomini ... ne mostrano le cagioni delle cose. gli effetti delle virtu e de vizi, $e$ che fuggire dobiamo e che seguires (Trattattello in laude di Dante, 472.473, 141142). "res que a present bages vist o oyt no tengues celat a mos amichs e servidors ... per tal com seran certs de moltas cosas en què no solament alguns d'ells dubten, mas la major part dels hòmens, e signantment ignorants ... lexa anar la ayga per lo riu, que abans que ns partiscam, si subtilment hi volràs specular, conexeràs gran part del misteri que-sta amagat; però no.t faga cura de publicar aquell quant lo sabràs, car risch de gran perill te'n seguira e de poch proffit a present» (OBM II 252, 10-17 ... 256, 6-9). 
reserva, que hi és per contra a l'obra de Metge, que era un autèntic revulsiu. Ja va veure Hvizinga que en aquest sentit els italians eren encara molt medievals. Mentre que Metge no surt de la confidencialitat, en un llenguatge gairebé xifrat pel seu culturalisme. Intimitat i sentit estètic, elaborats dins un estricte racionalisme li van donar una fòmula vàlida per llegir-la al marge del pas del temps, dins d'un classicisme, $\mathbf{i}$-segons deia- per tenir ampli profit en el temps esdevenidor $(252,10-17)$.

L'operaciô d'abstracció o elevació, que d'una manera característica feia Petrarca, l'acompleix Metge, pujant-hi encara un esglaó; i no és altra cosa el que suposava l'Humanisme: la Griselda de Petrarca quant a la boccaccesca i la de Metge respecte al Griseldis. En darrera instància l'actitud humanista contempla l'home des d'una dimensió progressivament més completa i objectivada. Com bé palesen els textos literaris.

El de Metge ếs un diàleg obert, però no com el de Llull, en una dinàmica geogràfica o espacial, ans en la dimensió temporal, segons van iniciar els trescentistes, qui ho havien après dels clàssics. Es tracta en realitat de l'encontre del jo i l'altre, que es dóna en un profund rerefons de la intimitat del lector; àmbit aquest de l'alteritat a què només ens hi comencem a apropar. I que es descobreix a la Península en aquest diàleg; però no només per qüiestió del gènere ans per la mateixa concepció del text, la seva noblesa i les seves fonts.

Ací, no he fet una arreplega de totes les fonts que m'ha semblat anar trobant, ni pretenc que estiguin establertes d'una manera ferma. Sí, però, crec que interessa donar a conèixer la manera de fer de Metge i el seu tan noble tarannà, no només literari sinó també moral. Perquè és de suposar que això podrà contribuir a fomentar el seu estudi i coneixement. I alhora el reconeixement de més fonts, que entre tots -al cap de sis segles-, en una mena d'espectacle sorprenent, anem ensopegant.

$\mathrm{Si}$, segons el meu parer, serà difícil de mantenir una postura medievalitzant amb tot aquest bé de Déu de fonts al darrera, aquesta pruija per amagar-les i la nova lectura que se'n desprén, crec que alhora ens fan palès-com hem començat dient-, que ni el seu tractament ni els cabdals són diferents del que s'havia dit a la primera meitat del segle XX, sigui a l'anàlisi de BordoyTorrents o a l'aportació de les fonts literàries que recull l'edició del Dr.Riquer. Fonts que acabaran determinant el fons documental històric, que aparentment li era negatiu.

L'obra dels que hem de reconèixer com a humanistes 26 se situa en una dimensió atemporal car no busquen l'èxit del moment. Escriuen per a qui els pugui entendre i en tregui un profit moral. Per això la seva escritura és sagrada i l' amaguen amb un vel, com deia Bocccaccio $i$ hem vist suara.

26 Per a tot el relatiu a I'Humanisme a la Corona catalanoaragonesa cal remetre a Batllori 1995. 
Per acabar, em fixaré al final de Lo somni. Car no se'ns diu que Tirèsias ha de marxar perquè el crida Proserpina. Però això es fa ben palès a la sătira horaciana (II, 5) que es llegeix amagadament i persistent, de fons, com una ombra flagel.ladora.

Proserpina no hi és citada potser perquè no cal quan ja al poema horacià és ella qui fa veure que Tirèsias de fet no és ningú o és un ninot ${ }^{27}$. Totes dues obres, amb el mateix punt final, ens deixen amb el mateix dessabor a causa del malaurat endeví.

Lo somni tanca, així, d'una manera coherent amb les fonts inicials: les Confessions agustinianes, les quals ben havia assumit dins la seva tasca d'introspecció i coneixement del sant, i el Libre del gentil de Llull, d'on prenia l'actitud dialogadora, que li menava com al filòsof a fer un ferm reny per mitjà del gentil envers els cristians.

\section{REFERÈNCIES BIBLIOGRÀFIQUES}

AGusti, sant, Obras de san Agustín, t. III, Obras filosóficas, BAC, Madrid 1982.

BADIA, Lola, Bernat Merge i els "auctores": del material de construcció al producte elaborat. «Boletín de la Real Academia de Buenas Letras de Barcelona» XLIII (1991-92), 25-40.

BATLLORI, M., De l'Humanisme i del Renaixement (Obra completa, V), ed. Tres i Quatre, Valencia 1995.

Boccaccio, Trattatello in laude di Dante, a III, Tutte le opere di Giovanni Boccaccio, ed. a cura de P. G. Ricci, «I Classici Mondadori», Amoldo Mondadori, Mila 1974.

Í., Opere in versi, Corbaccio. Traltatello in laude di Dante. Prose latine. Epistole, a IX, La Letteratura Italiana. Storia e testi, a cura de P. G. Ricci, ed. R. Ricciardi, Milà-Nàpols 1965.

İ., Decameron. Filocolo. Ameto. Fiammetta. VIII, La Letteratura Italiana. Storia e testi, a cura de E. Bianchi, C. Salinari, N. Sapegno. ed. R. Ricciardi, MilàNàpols1952.

ÍD., Il Comento alla Divina Commedia, I-III, a cura de D. Guerri, ed. G. Laterza, Bari 1918.

BORDOY-TORRENTS, P.. Les escoles dominicuna ifranciscanes en "Lo somni" de Bernat Metge, "Criterion" I (1925), 60-94.

ButTINYÃ I Jiménez, J ., Una nova font de "Lo somnin de Bernat Metge: Horaci, al"Homenatge al Dr. Joaquim Molas, Universitat de Barcelona, en premsa.

ÍD., Al voltunt de les obres més curtes de Metge, a l'Homenatge al professor Josep Tavani, Publicacions de l'Abadia de Montserrat, en premsa.

27 Això és especialment colpidor si Tirèsias fa -potser, i com a rereombra. de l'Església; però amb seguretat, gràcies a la font del Secretum- d'Agustí (Butinyà 1995 a). Però un Agustí capgirat o deturpat per Petrarca, quan bé hauria llegit Metge, al capitol que havia citat del $D e$ remediis (JJ, XCVJ, p. 164), qque els déus van posar a Tirèsias tota la llum al seu esperit. 
ÍD., Las ideas del "De Trinitate" agustiniano tras un reconocido "epicúreo": Bernat Metge, a l'Homenatge al professor Montoya, Universitat de Granada, en premsa.

Í., Al voltant dels conceptes de la gentilitat $i$ el profetisme a "Lo somni" de Bernat Metge i la font del "Secretum", «Llengua i Literatura. Revista anual de la Societat Calalana de Llengua i Literatura" 12, en premsa.

ID., Al voltant del final del llibre I de "Lo somni» de Bernal Metge i la qüestió de l'ànima dels unimals, "Butlleti de la Reial Acadèmia de Bones Lletres de Barcelona". en premsa.

Íb., Ciceró i Ovidi a «Lo somni», a «Jornada Medieval sobre Bernat Metge» (desembre 1999), Universitat de La Sorbona «Centre D’Études Catalans», París, en premsa.

ÍD., Un llibre català, un gentil italià i la cultura europea, al VIl Congresso Internazionale di Studi, Napoli (maig 2000): Napoli, Paesi Catalani, Europa. Momenti di cultura catalana in un millennio. Arte, letteratura, lingua e storia (actes en premsa).

Í., Barcelona, Nápoles y Valencia: tres momentos del Hamanismo en la Corcna de Aragón. al Seminari Interuniversitari La ciudad como espacio plural: historia y poética de lo urbano, dir. per E.Popeanga, UCM-UNED-CEU (maig 2000), en premsa.

Íb., Un altre Metge, si us plau. (Al voltant de la dissortada mort del rei Joan l a Foixà. a propoisit d' un parell de noves fonts de "Lo somni"), "Annals de l'Institut d'Estudis Gironins», XLI 2000 a), 27-50.

Ío., Tras los orígenes del Humanismo: El "Curial e Güelfa", UNED, Madrid 2." ed. $2000 \mathrm{~b}$

ÍD., 600 anys de "Lo somni», el primer diàleg humanístic de la Penínsuia, «Revista de Filologia Románica» $17(2000 \mathrm{c}), 293-315$.

ÍD. (coord.), Literatura Catalana, III: Siglo XX. UNED, Madrid 1999.

ÍD., Sobre la font a" una font del "Tirant lo Blanch" i la modernitat de la novel.la, a les Actes del Simposi: Creativitat ara: "Tirant lo Blanc". Temes i problemes de recepció i traducció literàries (Institut Interuniversitari de Filologia Valenciana, L'Alfàs del Pi 1997), "Caplletra» 23 (1998), 57-74.

ÍD., Sobre la proyección de los trecentistas italianos en la introducción del humanismo en la Corona de Aragón, «Cuademos de Filología Italiana» IV (1997 a), UCM, 265-277.

Ív., La influencia de Metge sobre Martorell: la sombra de 'Lo Somni' sobre el 'Tirant lo Blanc'. Actes del VI Congrés de l'Associació Hispànica de Literatura Medieval. Alcalá de Henares 1997 b, 381-391.

ÍD., Bernat Metge y el primer momento humanista, en Literatura Catalana. 1 : Edad Media, UNED, Madrid 1997 c, 205-233.

Í., Sobre el prólogo de Ferrer Sayol al "De re rusticas de Paladio, "Epos» XII (1996 a), 207-228.

ÍD., No busquem Llall entre els savis, «Revista de L'Alguer» 6 (1996 b), 215-228.

ÍD. La conciencia lingüistica en las letras catalanas de la Edad Media: del campo histórico y del filosófico al de la ficción, en Emma Martinell, Mar Cruz (eds.): La conciencia lingüistica en Europa, PPU. Universitat de Barcelona 1996 c, 79-134.

ÍD., Cicerôn, Ovidio, Agustín y Petrarca tras «Lo Somni» de Bernat Metge «Epos» X (1995 a), 173-201.

ÍD. El diálogo de Bernat Metge con Ramon Llull. Dos nuevas fuentes tras «Lo Somni», en Actes del V Congrés de l'Associació Hispànica de Literatura Medieval, Granada 1995 b. 429-444.

ÍD., "Jo començ allà on deig. car Job no fou jueu ans fou ben gentil", a Miscellània Germà Colón, IV, Publicacions de l'Abadia de Montserrat 1995 c. $37-54$. 
ÍD., Metge, un bon lul.lista i admirador de Sant Agusti, «Revista de Filología Románican XI-XII (1994-95), 149-170.

ID., Dues esmenes al "De remediis» $i$ dues adhesions al "Somnium Scipionis» en el prehumanisme català, «Revista de L'Alguer» V (1994 a), 195-208.

Í., De Metge a Petrarca pasando por Boccaccio, «Epos» IX (1994 b), 217-231.

ID., Bernat Metge y su terrorifica amante. (Una relectura de "Lo Somni»), «Antipodas. Joumal of Hispanic Studies” V (1993 a), 129-141.

ÍD. Una volta per les obres de Metge de la mà de Fortuna i de Prudència, a Miscel.lània Jordi Carbonell III, Publicacions de l'Abadia de Montserrat 1993 b, 45-70.

Íb., El paso de "Fortuna" por la Peninsula durante la baja Edad Media, «Medievalismo. Boletín de la Sociedad Española de Estudios Medievales» IIl (1993 c), 209232.

ÍD., Un nou nom per al vell del "Llibre de Fortuna e Prudència", "Boletín de la Real Academia de Buenas Letras de Barcelona» XLII (1989-90), 221-226.

CiCeró, Caton l'Ancien. De la vieillesse, "Les Belles Lettres", a cura de P. Wuilleumier, París 4." ed. 1989 a.

Í., De amicitia, ed.a cura de V. García Yebra, 2." ed.. Gredos, Madrid 1989 b.

Cingolani, S.M., «Lo somni" de Bernat Metge: prolegòmens per a una nova edició. «Llengua i Literatura. Revista anual de la Societat Catalana de Llengua i Literatura» 10 (1999), 245-278.

Curtius, E. R., Literatura europea y Edad Media Latina, I, Fondo de Cultura Económica, 5." ed. Madrid 1989.

DANTE, Divina Comèdia, 1, «Els Nostres Clàssics», a cura d'A. M. Gallina, ed. Barcino, Barcelona 1974.

JuveNAL, Satires, «Les Belles Lettres», a cura de P. Labriolle i F. Villeneuve, 11." ed. París 1974.

PetrarCa, La medida del hombre. Remedios contra la buena y la mala suerte, a cura de J. M. Micó, ed. Península, Barcelona 1999.

ÍD., Opere, a cura d'E. Bigi, ed. Ugo Mursia, 2." ed. Milán 1964.

ÍD., La Letteratura italiana. Storia e testi, VII, Prose, a càrrec de G.Martellotti, P. G. Ricci, E. Carrara, E. Bianchi, Milà-Nàpols 1955.

RiQuer, Marti de, Obras de Bernat Metge, Universitat de Barcelona 1959. (OBM) 